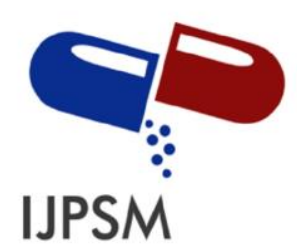

Dida Putri et al, Int. Journal of Pharmaceutical Sciences and Medicine (IJPSM),

Vol.6 Issue. 1, January- 2021, pg. 92-98

ISSN: 2519-9889

Impact Factor: 3.426

\title{
Review: Multi-Component Crystals: Cinnamic Acid As A Co-Former
}

\author{
Dida Putri ${ }^{1}$; Maria Dona Octavia ${ }^{1}$; Indra Makmur ${ }^{1}$; Harrizul Rivai ${ }^{2}$ \\ ${ }^{1}$ School of Pharmaceutical Science (STIFARM) Padang 25174, Indonesia \\ ${ }^{2}$ Faculty of Pharmacy, Andalas University, Limau Manih Campus, Padang 25163, Indonesia \\ E-mail: didaputri.01@gmail.com \\ DOI: 10.47760/ijpsm.2021.v06i01.008
}

\begin{abstract}
Each drug compound has a different level of solubility. The active pharmaceutical ingredient (API) solubility in water is one of the critical parameters in the biological activity of drugs. To overcome this problem, it can use multi-component crystals with a cinnamic acid co-former to improve drugs' physicochemical properties because it is necessary to look for information on how to manufacture multi-component crystals. Data resources were collected from Google Scholar, PubChem, Researchgate, and all available literature from 2000-2020. This review aims to examine the effect of multi-component crystals using a cinnamic acid co-former on drugs' physicochemical properties in terms of their solubility. Several methods used in the manufacture of multi-component crystals are solvent evaporation, slow cooling, solvent drop grinding, solution cocrystallization, and liquid-assisted grinding. The results show that multi-component crystals using cinnamic acid coformer can improve the physicochemical properties of drug inactive compounds carbamazepine, itraconazole, ibuprofen, moxifloxacin, isoniazid, and lovastatin. So it can be concluded that the active substance formed with multi-component crystals using a cinnamic acid co-former effectively improves the active substance's solubility.
\end{abstract}

Keywords: multi-component crystals, cinnamic acid, solubility

\section{Introduction}

One of the factors affecting the bioavailability of drugs is solubility [1]. The active pharmaceutical ingredient (API)'s water solubility is the most critical physicochemical parameter for determining aspects of drug formulation and delivery. In the development of drugs, solubility is a challenge in formulating pharmaceutical ingredients (API) because they directly affect drugs' biological activity [2]. In this case, a multi-component crystal is an effective method because it can improve the physicochemical properties of active pharmaceutical ingredients (API), such as solubility, stability, melting point, and dissolution rate [3]. Multi-component crystals are formed when more than one molecule of different substances crystallize together in a crystal lattice using non-covalent bonds with a stoichiometric ratio. The multi-component forms of crystals include cocrystal, hydrate, and salt $[4,5]$. Cocrystal is a multi-component crystalline material, a stable reactant molecule consisting of active drug and co-formers, solid in its pure state [6]. Hydrate is a crystalline solid containing the active pharmaceutical ingredient (API) molecule and a water molecule or other solvent known as a form of pseudopolymorphic [7].

Several methods can be used to make multi-component crystals: solvent evaporation, slow cooling, solvent drop grinding, solution cocrystallization, and liquid-assisted grinding. Cinnamic acid used as a constituent of multi-component crystals is expected to transform the physicochemical properties of the active pharmaceutical ingredient (API) so that the formation of multi-component crystals can significantly increase the benefits of 


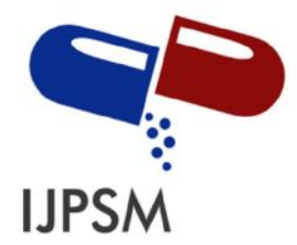

Dida Putri et al, Int. Journal of Pharmaceutical Sciences and Medicine (IJPSM), Vol.6 Issue. 1, January- 2021, pg. 92-98

ISSN: 2519-9889

Impact Factor: 3.426

active pharmaceutical ingredients (API). This review aims to see the effect of multi-component crystals using a cinnamic acid co-former on drugs' physicochemical properties in terms of their solubility.

\section{Data Collection}

In compiling the review article, the technique used in literature studies by finding scientific sources or pharmaceutical literature in primary data or the form of official books and national and international journals within the last 20 years (2000-2020). In the writing of this review article, research data were obtained by using online media with the keywords multi-component crystals, cinnamic acid, and solubility. The primary searching of the references used in this review article is through trusted websites such as Google Scholar, PubChem, Researchgate, and other published and trustworthy journals.
\end{abstract}

\title{
Definition of Multi-Component Crystals
}

Multi-component crystals are crystals with two or more differences (2D structure and elements) or other differences but do not have opposite chiral [8]. Crystalline multi-components are salt crystals, solvents, and hydrates, increasing the solvency, dissolution rate, physical and chemical stability, and compressibility by changing the physicochemical properties of a drug for the formation of new phases through crystal engineering techniques $[9,10]$. The classification of multi-component crystals is divided into cocrystal, hydrate, and salt. Cocrystal is a solid crystal containing more than one solid component that aims to modify the active pharmaceutical ingredient (API). Cocrystal contains active pharmaceutical ingredients (API), and conformers or crystal formers are generally considered safe ingredients for human consumption [11]. Cocrystal is two or more solid molecules that form a different crystal lattice and are connected by bonds between molecules such as hydrogen bonds and Van der Waals forces. The technique of cocrystallization is a simple method to increase the solubility and bioavailability of drugs that are difficult to dissolve in water with better physicochemical properties.

The advantage of this cocrystallization method is that it can improve the active substance's physical properties without affecting its pharmacological activity [12,13]. Salt is the most preferred solid form to increase the active pharmaceutical ingredient (API) due to its greater affinity for water molecules [11]. Salt contains one ionic compound but has many ions. It involves the transfer of protons from acid to base in the process of formation [14]. The difference between salt and cocrystal is that salt is generally directed at one acid and base functional group. It can simultaneously be at several active groups in one drug molecule in cocrystal and not limited to acid and base pairs [15,16]. Hydrate is included as a solvate class where water molecules are included in the pharmaceutical ingredient's crystalline lattice (API) [17]. The hydrate crystal contains a solid component and a liquid component [5]. Hydrate is a crystal with a solvent molecule added with a co-former or two ions [8]. It also indicates a water-containing substance [18]. Hydrates have atmospheric humidity, small water molecules, and water to act as a hydrogen donor and acceptor. Solvates and hydrates increase the number of cocrystal related solids [19].

\section{Cinnamic Acid Coformer}

In developing a multi-component crystal, the selected co-former should not affect the pharmacological activity of the active pharmaceutical ingredient (API) and the co-former chosen from the list of generally recognized as safe (GRAS) chemicals [20]. GRAS chemicals are food additives that are safe for human consumption [21]. In the selection of conformers, there are three kinds of theories that can be used. They are the pharmaceutical Sinton approach, the pKa approach, and the solubility approach. Pharmaceutical Sinton theory states that the former to be used must have a functional group complementary to the active drug group [22].

Cinnamic acid is also known as (E) -Cinnamic or trans-Cinnamic and belongs to a class of organic compounds known as cinnamic acids. The chemical formula for cinnamic acid is $\mathrm{C} 9 \mathrm{H} 8 \mathrm{O} 2$ with a molecular weight of $148.16 \mathrm{~g} / \mathrm{mol}$. Cinnamic acid is an aromatic organic compound containing benzene and a carboxylic acid group that forms 3-phenyl prop-2-enoic acid. Other names for cinnamic acid are cinnamic acid, trans-Cinnamic acid, 


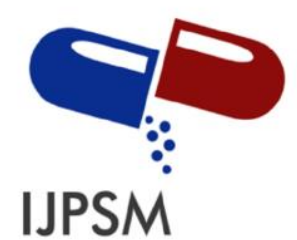

Dida Putri et al, Int. Journal of Pharmaceutical Sciences and Medicine (IJPSM), Vol.6 Issue. 1, January- 2021, pg. 92-98

ISSN: 2519-9889

Impact Factor: 3.426

(E) -Cinnamic acid, Phenylacrylic acid, 3-Phenylacrylic acid, Benzeneproprnoic acid [23]. Cinnamic acid has a boiling point value of $300^{\circ} \mathrm{C}$ and a melting point of $134^{\circ} \mathrm{C}$ [24]. The structure of cinnamic acid can be seen in (Figure 1). Cinnamic acid has been widely used as a co-former in the formation of multi-component crystals with carbamazepine [25], itraconazole [26], AMG 517 [27], ibuprofen [28], moxifloxacin [29], isoniazid [30], and lovastatin [31].<smiles>O=C(O)C=Cc1ccccc1</smiles>

Figure 1: Chemical Structure of Cinnamic Acid [23]

\section{Methods of Production}

\section{Solvent evaporation}

Solvent evaporation is the most common method used in forming multi-component crystals where the drug and co-former with a stoichiometric ratio are dissolved using a specific solvent, stirred under stable conditions to facilitate the interaction between the drug and the former. Then the solvent is allowed to evaporate to form multi-component crystals [22].

\section{Slow cooling}

In this cooling method, the process of crystallization involves temperature variations. This method is done by mixing numerous reactants and solvents in a reactant, generally a rubber vessel, then the system is heated to a higher temperature. This process aims to ensure that all components dissolve in the solvent, to be cooled down to form crystals later on [32].

\section{Solvent drop grinding}

This method is a modification of the neat grinding carried out by adding a small amount of solvent during the milling process to increase the supramolecular selectivity [33]. This method involves mixing the two components by adding a small amount of solvent. Advantages of this method lie in the improvement of workability. The ability to control the production of polymorphs and most of the co-former are suitable for this method [34].

\section{Solution cocrystallization}

In solution crystallization, several things become strategies using a solvent or mixed solvent in which the crystals are saturated so that the components have the same solubility and use non-equivalent concentrations to achieve stable crystals [35,36].

Based on the research article, the multi-component crystals modification method using cinnamic acid conformers can improve drugs' physicochemical properties (Table 1). 


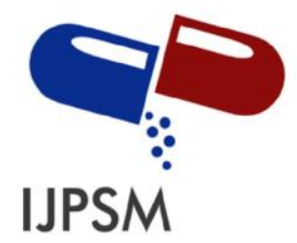

Dida Putri et al, Int. Journal of Pharmaceutical Sciences and Medicine (IJPSM), Vol.6 Issue. 1, January- 2021, pg. 92-98

ISSN: 2519-9889

Impact Factor: 3.426

Table I: The modification result of multi-component crystals using a cinnamic acid co-former.

\begin{tabular}{|c|c|c|c|c|}
\hline No. & Active Substance & Method & Result & Ref \\
\hline 1 & Carbamazepine & Solvent evaporation & $\begin{array}{l}\text { Cocrystal CBZ-CIN was characterized using } \\
\text { DSC, PXRD, and FT-IR tools. The solubility } \\
\text { concentration and dissolution rate of CBZ-CIN } \\
\text { cocrystal were higher than pure CBZ, CBZ } \\
\text { dissolved as much as } 80 \% \text { in the first } 20 \\
\text { minutes, and cocrystal was stable in the } \\
\text { dissolution medium. }\end{array}$ & [25] \\
\hline 2 & Itraconazole & Solvent evaporation & $\begin{array}{l}\text { Cocrystal ITZ-TCA was characterized using } \\
\text { PXRD, DSC, TGA, and FT-IR tools. The } \\
\text { solubility of cocrystal ITZ-TCA was } 1.97 \text { times } \\
\text { higher than pure ITZ after } 24 \text { hours. }\end{array}$ & [26] \\
\hline 3. & AMG 517 & Slow cooling & $\begin{array}{l}\text { Cocrystal was characterized using DSC and } \\
\text { XRPD tools. The results showed a good } \\
\text { correlation between the co-former and cocrystal } \\
\text { melting point but had a smaller correlation } \\
\text { between the melting point and the solubility of } \\
\text { cocrystal. }\end{array}$ & [27] \\
\hline 4. & Ibuprofen & $\begin{array}{l}\text { Solvent } \\
\text { grinding }\end{array}$ & $\begin{array}{l}\text { Cocrystal IBU-CIN was characterized using IR } \\
\text { spectroscopy, DSC, XRD, and SEM. The } \\
\text { solubility test and dissolution rate increased } \\
\text { three times faster than pure ibuprofen in } 60 \\
\text { minutes. }\end{array}$ & [28] \\
\hline 5. & Moxifloxacin & $\begin{array}{l}\text { Solution } \\
\text { cocrystallization }\end{array}$ & $\begin{array}{l}\text { Moxifloxacin-cinnamic acid was characterized } \\
\text { using XRPD, ATR-FTIR, and SSNMR tools. } \\
\text { The solubility test and dissolution rate of } \\
\text { moxifloxacin showed a reduction up to } 3 \text { times } \\
\text { lower than pure moxifloxacin. }\end{array}$ & [29] \\
\hline 6. & Isoniazid & $\begin{array}{l}\text { solution } \\
\text { crystallization } \\
\text { Liquid-assisted } \\
\text { grinding }\end{array}$ & $\begin{array}{l}\text { Cocrystal isoniazid-cinnamic acid was } \\
\text { characterized using single-crystal X-ray } \\
\text { diffraction, PXRD, and thermal analysis. The } \\
\text { stability test shows that cocrystal is stable for a } \\
\text { long time, and the solubility tends to increase } \\
\text { with the increase of acid solubility. }\end{array}$ & [30] \\
\hline 7. & Lovastatin & $\begin{array}{l}\text { Liquid-assisted } \\
\text { grinding }\end{array}$ & $\begin{array}{l}\text { Lovastatin-cinnamic was characterized using } \\
\text { DSC, PXRD, FT-IR, and SEM tools. The } \\
\text { results showed that the solubility was four } \\
\text { times more soluble than pure lovastatin. }\end{array}$ & [31] \\
\hline
\end{tabular}

Synthesis of cocrystal carbamazepine with cinnamic acid co-former use the solvent evaporation method. Cocrystal was characterized using the DSC, PXRD, and FT-IR tools. DSC is used to assess the thermal properties of cocrystal, the results of the thermogram show the melting point of cocrystal CBZ-CIN at $144^{\circ} \mathrm{C}$. PXRD was determined using a $2 \Theta\left(4-40^{\circ}\right) \mathrm{X}$-ray diffractometer. The results showed the emergence of new diffraction peaks indicating cocrystal formation, and FT-IR was used to record the sample's IR spectrum. The results showed the formation of hydrogen bonds between CBZ and CIN due to interaction between CBZ and CIN. The concentration of CBZ-CIN was determined by the NASSAM method (net analyte signal standard addition method) using a UV-Vis spectrophotometer, and the absorption spectrum was seen at a wavelength of 200-400 nm. The solubility test shows that CBZ-CIN cocrystal has a higher solubility than pure CBZ. The solubility concentration obtained from cocrystal $\mathrm{CBZ}-\mathrm{CIN}$ at $37^{\circ} \mathrm{C}$ is around $306 \mathrm{ppm}$, while pure $\mathrm{CBZ}$ is 


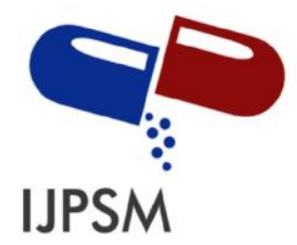

\section{Dida Putri et al, Int. Journal of Pharmaceutical Sciences and Medicine (IJPSM), Vol.6 Issue. 1, January- 2021, pg. 92-98}

ISSN: 2519-9889

Impact Factor: 3.426

about $262 \mathrm{ppm}$. At the dissolution rate, the results showed that CBZ-CIN cocrystal was higher than pure CBZ, and cocrystal was stable in the dissolution medium. The amount of dissolved CBZ from cocrystal CBZ-CIN was $80 \%$ in the first 20 minutes [25].

This research was conducted to synthesize cocrystal ITZ with a trans-cinnamic acid co-former using the solvent evaporation method. Cocrystal was characterized using PXRD, DSC, TGA, and FT-IR tools. The analysis of PXRD and DSC shows the formation of a new phase which is marked in a different pattern of itraconazole cocrystal, this occurs due to changes in crystal structure caused by the interaction between the active substance and the co-former, whereas the DSC cocrystal ITZ thermogram shows crystal purity characterized by a single melting endotherm and the melting point for cocrystal ITZ-TCA was $142.35^{\circ} \mathrm{C}$. The TGA test was carried out to see the cocrystal weight changes associated with temperature changes, and the weight loss of cocrystal is $16.99 \%$. FT-IR aims to prove the formation of multi-component crystals, FT-IR spectra confirmed the presence of new crystal multi-components characterized by a change in the O-H strain frequency. The ITZ concentration was analyzed using HPLC at a wavelength of $261 \mathrm{~nm}$, and the solubility of crystal ITZ-TCA in $\mathrm{HCl} 0.1 \mathrm{~N}$ (pH 1.2) after 24 hours was 1.97 times higher than the pure ITZ. The solubility concentration of ITZ-TCA cocrystal is $9.846 \mathrm{ppm}$. These results indicate that the TCA co-former can change the physicochemical properties of ITZ, and the cocrystallization technique can modify the solubility of ITZ [26].

Stanton \& Annette (2008) have synthesized cocrystal AMG517 using the slow cooling method. Cocrystal is made based on thermal analysis, values of ${ }^{1} \mathrm{H}$ NMR and pKa, and analyzed using DSC and XRPD tools. The cocrystal tested physicochemical properties were particle size, solubility, stability, hygroscopicity, thermal properties, and hydrogen-bonds network. In the solubility test, the concentration of cocrystal AMG517-TCA showed lower solubility than the solubility of the free base AMG517, with a solubility value of less than 3 $\mu \mathrm{g} / \mathrm{mL}$. The results showed that there was a single crystalline structure. It had the same two hydrogen bonds between the active ingredient and the co-former and had a good correlation (78\%) between the melting point of the co-former and cocrystal, but had a smaller correlation $(55 \%)$ between the melting point and the solubility of cocrystal [27].

Gangadhar et al. (2014) researched cocrystal ibuprofen using the solvent drop grinding method and characterized using IR spectroscopy, DSC, XRD, and SEM. The DSC thermogram test shows that the formation of a new phase of cocrystal is marked at the maximum endothermic peak at $66.14^{\circ} \mathrm{C}$, and the XRD test shows an intense peak movement at $16.3^{\circ} \mathrm{C}$, indicating the cocrystal character of IBU-CIN. The SEM test showed a needle-shaped surface, changes in surface morphology, irregular crystal development, and the melting point of cocrystal showed a decrease at a temperature of $56-62^{\circ} \mathrm{C}$. The solubility of cocrystal IBU-CIN shows an increase of 3 times faster than the pure ibuprofen within 60 minutes, and the dissolution rate is also shown to be faster than the pure ibuprofen. The solubility concentration of cocrystal increased to 3.49 times compared to the pure ibuprofen with a solubility value of $1.41 \mathrm{mg} / \mathrm{mL}$ [28].

Eedara et al. (2019) synthesized a mixture of moxifloxacin with trans-cinnamic acid aiming to reduce the solubility and dissolution rate of the drug to increase the residence period in the lungs. Moxifloxacin-cinnamic acid was characterized using the XRPD, ATR-FTIR, and SSNMR tools. The PXRD test results showed new diffraction peaks at $7.3^{\circ}, 8.9^{\circ}, 17.6^{\circ}$, and $21.1^{\circ}$. The ATR-FTIR spectrum test indicates that a peak position shift characterizes hydrogen bonds between moxifloxacin and cinnamic acid. The concentrations of moxifloxacin and cinnamic acid were measured with HPLC. The results showed that moxifloxacin's solubility was three times lower than the pure moxifloxacin, with a decrease in solubility from $17.68 \pm 0.85 \mathrm{mg} \mathrm{mL}^{-1}$ to $6.10 \pm 0.05 \mathrm{mg} \mathrm{mL}^{-1}$ in phosphate buffer saline solution, $\mathrm{pH} \mathrm{7,4}$. The dissolution rate showed a decline up to 3.5 times slower than pure moxifloxacin, with a decrease from $0.47 \pm 0.04 \mathrm{mg} \mathrm{cm}^{-2} \mathrm{~min}^{-1}$ to $0.14 \pm 0.03 \mathrm{mg}$ $\mathrm{cm}^{-2} \mathrm{~min}^{-1}$. In the dissolution rate test, the inhaler's aerosolization properties showed a fine particle fraction of $30.4 \pm 1.2 \%$ [29]. 


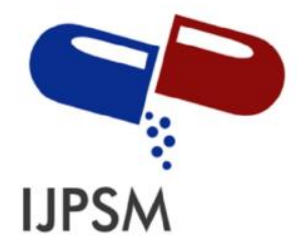

\section{Dida Putri et al, Int. Journal of Pharmaceutical Sciences and Medicine (IJPSM), Vol.6 Issue. 1, January- 2021, pg. 92-98}

ISSN: 2519-9889

Impact Factor: 3.426

Sarcevica et al. (2013) conducted a synthesis of cocrystal isoniazid using solution crystallization and liquidassisted grinding methods. The cocrystal formed was characterized using a single-crystal X-ray device in reaction, PXRD, and thermal analysis. The analysis of crystal structure showed the presence of different supramolecular Sinton. In this study, the stability test showed that cocrystal isoniazid-cinnamic acid at $30^{\circ} \mathrm{C}$ and $75 \% \mathrm{RH}$ was stable for an extended period during the 11-week experimental period. The solubility test showed cocrystal isoniazid was significantly different from pure isoniazid, which tended to increase by the increase of acid solubility [30].

In lovastatin synthesis, it is made with a mixture of binary and eutectic using the liquid-assisted grinding method, then characterized using the DSC, PXRD, FT-IR, and SEM tools. The combination results of this test show that a eutectic mixture is formed in the system. The SEM test showed a very different morphology compared to pure lovastatin. Lovastatin-cinnamate includes a eutectic system at a mole fraction of 0.14 . The solubility of lovastatin-cinnamate in the eutectic composition of the phase and Tammann diagrams was $187 \pm 5$ $\mu \mathrm{g} / \mathrm{mL}$, and the composition obtained by observing the DSC curve was $163.7 \pm 0.2 \mu \mathrm{g} / \mathrm{mL}$. In contrast, the solubility of pure lovastatin is $49 \pm 4 \mathrm{ug} / \mathrm{mL}$. This eutectic system showed an increase in lovastatin's solubility to be four times more soluble than pure lovastatin, and the lovastatin eutectic system is promising for use in a strategy of solubility improvement [31].

\section{Conclusion}

Multi-component crystal is a modification technique to improve drugs' physicochemical properties to reach the maximum therapeutic effect. Several methods used in the manufacture of multi-component crystals are solvent evaporation, slow cooling, solvent drop grinding, solution cocrystallization, and liquid-assisted grinding. The results show that multi-component crystals using a cinnamic acid co-former can rectify the physicochemical properties of drugs and help improve the solubility of the active substance.

\section{References}

[1] Pawar SR, Barhate SD. Solubility enhancement (Solid Dispersions) novel boon to increase bioavailability. J Drug Deliv Ther. 2019;9(2):583-90.

[2] Lipinski CA. Drug-like properties and the causes of poor solubility and poor permeability. J Pharmacol Toxicol Methods. 2000;44:235-49.

[3] Morissette SL, Almarsson Ö, Peterson ML, Remenar JF, Read MJ, Lemmo A V., et al. High-throughput crystallization: Polymorphs, salts, cocrystals and solvates of pharmaceutical solids. Adv Drug Deliv Rev. 2004;56(3):275-300.

[4] Putra OD, Uekusa H. Pharmaceutical Multicomponent Crystals: Structure, Design, and Properties. (eds.), Ad. Sakamoto M, Uekusa H, editors. Singapore: Springer Nature Singapore Pte Ltd; 2020. 153-180 p.

[5] Aitipamula S, Banerjee R, Bansal AK, Biradha K, Cheney ML, Choudhury AR, et al. Polymorphs, salts, and cocrystals: What's in a name? Cryst Growth Des. 2012;12(5):2147-52.

[6] Vishweshwar P, McMahon JA, Peterson ML, Hickey MB, Shattock TR, Zaworotko MJ. Crystal engineering of pharmaceutical cocrystals from polymorphic active pharmaceutical ingredients. Chem Commun. 2005;(36):4601-3.

[7] Healy AM, Worku ZA, Kumar D, Madi AM. Pharmaceutical solvates, hydrates and amorphous forms: A special emphasis on cocrystals. Adv Drug Deliv Rev [Internet]. 2017;117:25-46. Available from: http://dx.doi.org/10.1016/j.addr.2017.03.002

[8] Grothe E, Meekes H, Vlieg E, Ter Horst JH, De Gelder R. Solvates, Salts, and Cocrystals: A Proposal for a Feasible Classification System. Cryst Growth Des. 2016;16(6):3237-43.

[9] Putra OD, Furuishi T, Yonemochi E, Terada K, Uekusa H. Drug-Drug Multicomponent Crystals as an Effective Technique to Overcome Weaknesses in Parent Drugs. Cryst Growth Des. 2016;16(7):3577-81.

[10] Ainurofiq A, Mauldin R, Mudhakir D, Umeda D, Soewandhi SN, Putra OD, et al. Improving mechanical properties of desloratadine via multi-component crystal formation. Eur J Pharm Sci. 2018;111(September 2017):65-72.

[11] Aitipamula S, Tan RB. Pharmaceutical cocrystals : crystal engineering and applications. Tiekink ERT., ZukermanSchpector J, editors. Germany; 2018. 1-2 p. 


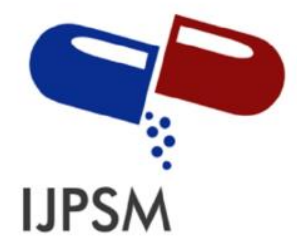

\section{Dida Putri et al, Int. Journal of Pharmaceutical Sciences and Medicine (IJPSM), Vol.6 Issue. 1, January- 2021, pg. 92-98}

[12] Douroumis D, Ross SA, Nokhodchi A. Advanced methodologies for cocrystal synthesis. Adv Drug Deliv Rev [Internet]. 2017;117:178-95. Available from: http://dx.doi.org/10.1016/j.addr.2017.07.008

[13] Zaini E, Halim A, Soewandhi SN, Setyawan D. Peningkatan Laju Pelarutan Trimetoprim Melalui Metode KoKristalisasi Dengan Nikotinamida. J Farm Indones. 2011;5(4) pp(March 2014):205-12.

[14] Patrick Stahly G. A survey of cocrystals reported prior to 2000. Cryst Growth Des. 2009;9(10):4212-29.

[15] Trask A V., Motherwell WDS, Jones W. Physical stability enhancement of theophylline via cocrystallization. Int J Pharm [Internet]. 2006 Aug 31;320(1-2):114-23. Available from: https://linkinghub.elsevier.com/retrieve/pii/S0378517306003395

[16] Almarsson Ö, Zaworotko MJ. Crystal engineering of the composition of pharmaceutical phases. Do pharmaceutical cocrystals represent a new path to improved medicines? Chem Commun. 2004;(17):1889-96.

[17] Almarsson Ö, Peterson ML, Zaworotko M. The A to Z of pharmaceutical cocrystals: A decade of fast-moving new science and patents. Pharm Pat Anal. 2012;1(3):313-27.

[18] Nugrahani I, Ibrahim S, Mauldin R, Krishnamurthi P. Studi Transformasi Hidrat Sefadroksil Monohidrat dan Sefaleksin Monohidrat dengan FTIR. J Mat Sains. 2013;18(1):1-10.

[19] Rodríguez-Spong B, Price CP, Jayasankar A, Matzger AJ, Rodríguez-Hornedo N. General principles of pharmaceutical solid polymorphism: A supramolecular perspective. Adv Drug Deliv Rev. 2004;56(3):241-74.

[20] Thayyil AR, Juturu T, Nayak S, Kamath S. Pharmaceutical Co-Crystallization: Regulatory Aspects, Design, Characterization, and Applications. Adv Pharm Bull. 2020;10:203-12.

[21] https://id.wikipedia.org/wiki/Umumnya_diakui_aman [Internet]. [cited 2020 Sep 15].

[22] Thakuria R, Delori A, Jones W, Lipert MP, Roy L, Rodríguez-Hornedo N. Pharmaceutical cocrystals and poorly soluble drugs. Int $\mathrm{J}$ Pharm [Internet]. 2013;453(1):101-25. Available from: http://dx.doi.org/10.1016/j.ijpharm.2012.10.043

[23] https://pubchem.ncbi.nlm.nih.gov/compound/444539\#section=Synonyms [Internet]. [cited 2020 Sep 15].

[24] https://en.wikipedia.org/wiki/Cinnamic_acid [Internet]. [cited 2020 Sep 15].

[25] Shayanfar A, Asadpour-Zeynali K, Jouyban A. Solubility and dissolution rate of a carbamazepine-cinnamic acid cocrystal. J Mol Liq [Internet]. 2013;187:171-6. Available from: http://dx.doi.org/10.1016/j.molliq.2013.06.015

[26] Hiendrawan S, Veriansyah B, Tjandrawinata RR. Solid-state properties and solubility studies of novel pharmaceutical cocrystal of itraconazole. Int J Appl Pharm. 2018;10(5):97-104.

[27] Stanton MK, Bak A. Physicochemical properties of pharmaceutical cocrystals: A case study of ten AMG 517 cocrystals. Cryst Growth Des. 2008;8(10):3856-62.

[28] Gangadhar ZA, Bhaskar DA, Bhaskar GS, Bhanudas SR. Preparation and Characterization of Ibuprofen Cocrystals by Using Solvent Drop Grinding Method. World J Pharm Res. 2014;3(4):1392-402.

[29] Eedara BB, Tucker IG, Zujovic ZD, Rades T, Price JR, Das SC. Crystalline adduct of moxifloxacin with transcinnamic acid to reduce the aqueous solubility and dissolution rate for improved residence time in the lungs. Eur $\mathbf{J}$ Pharm Sci [Internet]. 2019;136(January):104961. Available from: https://doi.org/10.1016/j.ejps.2019.104961

[30] Sarcevica I, Orola L, Veidis M V., Podjava A, Belyakov S. Crystal and molecular structure and stability of isoniazid cocrystals with selected carboxylic acids. Cryst Growth Des. 2013;13(3):1082-90.

[31] Araya-Sibaja AM, Vega-Baudrit JR, Guillén-Girón T, Navarro-Hoyos M, Cuffini SL. Drug solubility enhancement through the preparation of multi-component organic materials: Eutectics of lovastatin with carboxylic acids. Pharmaceutics. 2019;11(3):1-16.

[32] McNamara DP, Childs SL, Giordano J, Iarriccio A, Cassidy J, Shet MS, et al. Use of a glutaric acid cocrystal to improve oral bioavailability of a low solubility API. Pharm Res. 2006;23(8):1888-97.

[33] Jones W, Motherwell WDS, Trask A V. Pharmaceutical Cocrystals: An Emerging Approach to Physical Property Enhancement. MRS Bull [Internet]. 2006;31(November):875-9. Available from: http://m.jonesday.com/files/Publication/6c660a3c-9b3e-45be-9b10

0edd5a532f88/Presentation/PublicationAttachment/4a2ebdd9-a23f-412f-b41b

8bbc835be962/Trask_MRSBull_Nov06.pdf

[34] Yadav S, Gupta PC, Sharma N, Kumar J. Cocrystals: An Alternative Approach to Modify Physicochemical Properties of Drugs. Int J Pharm Chem Biol Sci. 2015;5:427-36.

[35] Ainouz A, Authelin JR, Billot P, Lieberman H. Modeling and prediction of cocrystal phase diagrams. Int J Pharm. 2009;374(1-2):82-9.

[36] Blagden N, Berry DJ, Parkin A, Javed H, Ibrahim A, Gavan PT, et al. Current directions in cocrystal growth. New J Chem. 2008;32(10):1659-72. 